\title{
Structure of Turbulent Nonpremixed Syngas Flames at High Pressure
}

\author{
Wesley R. Boyette ${ }^{\mathrm{a}, *}$, Thibault F. Guiberti ${ }^{\mathrm{a}}$, Gaetano Magnotti ${ }^{\mathrm{a}}$, William L. Roberts ${ }^{\mathrm{a}}$ \\ ${ }^{a}$ Clean Combustion Research Center, King Abdullah University of Science and Technology, Thuwal 23955-6900, Saudi Arabia
}

\begin{abstract}
The effects of both pressure and Reynolds number on the structure of turbulent nonpremixed flames are investigated experimentally. Syngas $\left(\mathrm{CO} / \mathrm{H}_{2} / \mathrm{N}_{2}\right)$ flames with constant composition are examined at pressures up to 12 bar and at Reynolds numbers up to 66,800 . The baseline atmospheric pressure flame is identical to the "chnA" flame of the Turbulent Nonpremixed Flames (TNF) Workshop. Low-speed OH-PLIF is used to reveal the flame structure in a small region 7 diameters downstream of the nozzle. The thickness of the $\mathrm{OH}$ layer decreases monotonically with pressure. Increasing pressure inhibits local extinction when comparing conditions at constant Reynolds number; an effect of changing exit strain rate. Neither changes in Reynolds number nor changes in pressure affect the mean flame front location. Corrugation of the flame front is highly sensitive to changes in Reynolds number but relatively insensitive to changes in pressure. Blow-off velocity limits the highest Reynolds number achievable by the TNF jet flames. By increasing the pressure, this ceases to be the limiting parameter, meaning that we can study the effect of Reynolds number on the structure of the Sandia-ETH syngas jet flame over a wider range of turbulence, approaching what is encountered in practical combustors.
\end{abstract}

Keywords:

High pressure, Turbulent nonpremixed flames, Syngas, Flame structure, OH-PLIF

\footnotetext{
${ }^{*}$ Corresponding author:

Email address: wesley.boyette@kaust. edu.sa (Wesley R. Boyette)
} 


\section{Introduction}

The Turbulent Nonpremixed Flames (TNF) Workshop was established more than 20 years ago to create a library of well-characterized flames and to facilitate collaborations between experimentalists and modelers at a time when advances in laser diagnostics and computational power were making such work possible. Initial work focused on investigations of simple flames using state-of-the-art combined diagnostics [1, 2], whereas more recent work has focused on more complicated flow fields [3-5] and fuels [6]. Absent from the progression to higher complexity has been a concerted effort to study the effects of pressure. To address this need, a new facility at KAUST has been designed to study turbulent nonpremixed flames at high pressure.

Syngas is an ideal fuel candidate for a high-pressure TNF case study for multiple reasons. A syngas flame already exists as one of the simple jet flames in the TNF Workshop [7, 8], so a well-characterized baseline atmospheric pressure condition is already available. Syngas flames are of interest scientifically because they are moderately more complex, in terms of chemical kinetics, than pure hydrogen flames [9]. Moreover, they are interesting in a practical sense because the very low sooting propensity makes them more amenable to advanced laser-based diagnostic techniques. While it has not previously been possible to study the behavior of turbulent nonpremixed syngas flames at high pressures, several studies on turbulent premixed syngas flames at gas turbine relevant conditions have been published. Such studies are often limited in scope and focus on the effects of changing Reynolds number while operating at elevated pressures, rather than observing the effects of changes in pressure $[10,11]$. In other cases, conditions over a range of pressures are investigated but the studies are unable to differentiate between effects of pressure and effects of Reynolds number [12, 13].

In this work, OH-PLIF is used to probe the structure of turbulent nonpremixed syngas flames over a wide range of pressures and Reynolds numbers. In doing so, it is possible to overcome Reynolds number limitations imposed by blow-off conditions at atmospheric pressure. Some effects may be anticipated from previous work. Increasing the jet Reynolds number tends to create more highly corrugated flame structures [14-16]. Increasing pressure is known to decrease flame thickness through its influence on reaction rate [17]. This has been demonstrated experimentally for methane-air [18] and methane-hydrogen-air [19]. Chemkin simulations of syngas flames also show that flame thickness monotonically decreases with pressure [20]. Experiments in turbulent premixed flames have shown that the Taylor microscale and Kolmogorov scale tend to decrease with increasing pressure, but the integral length scale becomes constant above 8 bar [21].

In keeping with the TNF Workshop's spirit of collaboration, the flames examined in this study are also wellsuited for validation of CFD models. Identification of the $\mathrm{OH}$ layer and the quantification of its thickness can be a useful metric for comparison with results of ongoing LES simulations [22, 23]. There is some precedent for using $\mathrm{OH}$ to indicate the reaction zone in pure $\mathrm{H}_{2}$ flames [24]. Generally, $\mathrm{OH}$ alone is not an ideal marker of the flame front, whereas the overlap of $\mathrm{OH}$ and $\mathrm{CH}_{2} \mathrm{O}$ is commonly used as such in hydrocarbon flames [25]. A recent DNS study of turbulent premixed syngas flames concludes that the product of $\mathrm{CH}_{2} \mathrm{O}$ and $\mathrm{OH}$ concentrations provides a good reconstruction of the heat release rate, but cautions that $\mathrm{CH}_{2} \mathrm{O}$ is a negligible side product in syngas flames [26]. Indeed, laminar flame simulations show that $\mathrm{CH}_{2} \mathrm{O}$ concentrations for the proposed fuel composition are orders of magnitude too low to be detected using current state-of-the-art and temporally resolved techniques such as PLIF. This was verified experimentally with unsuccessful attempts of $\mathrm{CH}_{2} \mathrm{O}$-PLIF. Accordingly, $\mathrm{OH}$ is the only available, viable marker for the flame front.

\section{Experiment}

Experiments are performed in the high pressure combustion duct (HPCD) now available in the Clean Combustion Research Center at KAUST. The HPCD has been designed to operate large turbulent non-premixed flames at pressures up to 40 bar. It is composed of four cylindrical sections of stainless steel pipe (ID $\approx 400$ $\mathrm{mm}$ ) in order to accommodate burners with an outside diameter up to $0.35 \mathrm{~m}$. Unlike other facilities that utilize a horizontal configuration, the vertical orientation of the 8-m tall rig ensures that long flames are not subject to asymmetric effects of buoyancy, which become more significant at high pressure. The optical section of the HPCD includes six windows, allowing for the application of a wide range of diagnostics. A cross section of the HPCD (optical section only) with a burner inside is shown in Fig. 1. Burners are positioned on a motorized, $1.5-\mathrm{m}$ stroke, vertical translation stage inside the duct, making it possible to completely probe very long flames. Regulation of the pressure in the HPCD is performed by a dome-loaded back pressure regulator located 2 meters downstream of the optical section. 


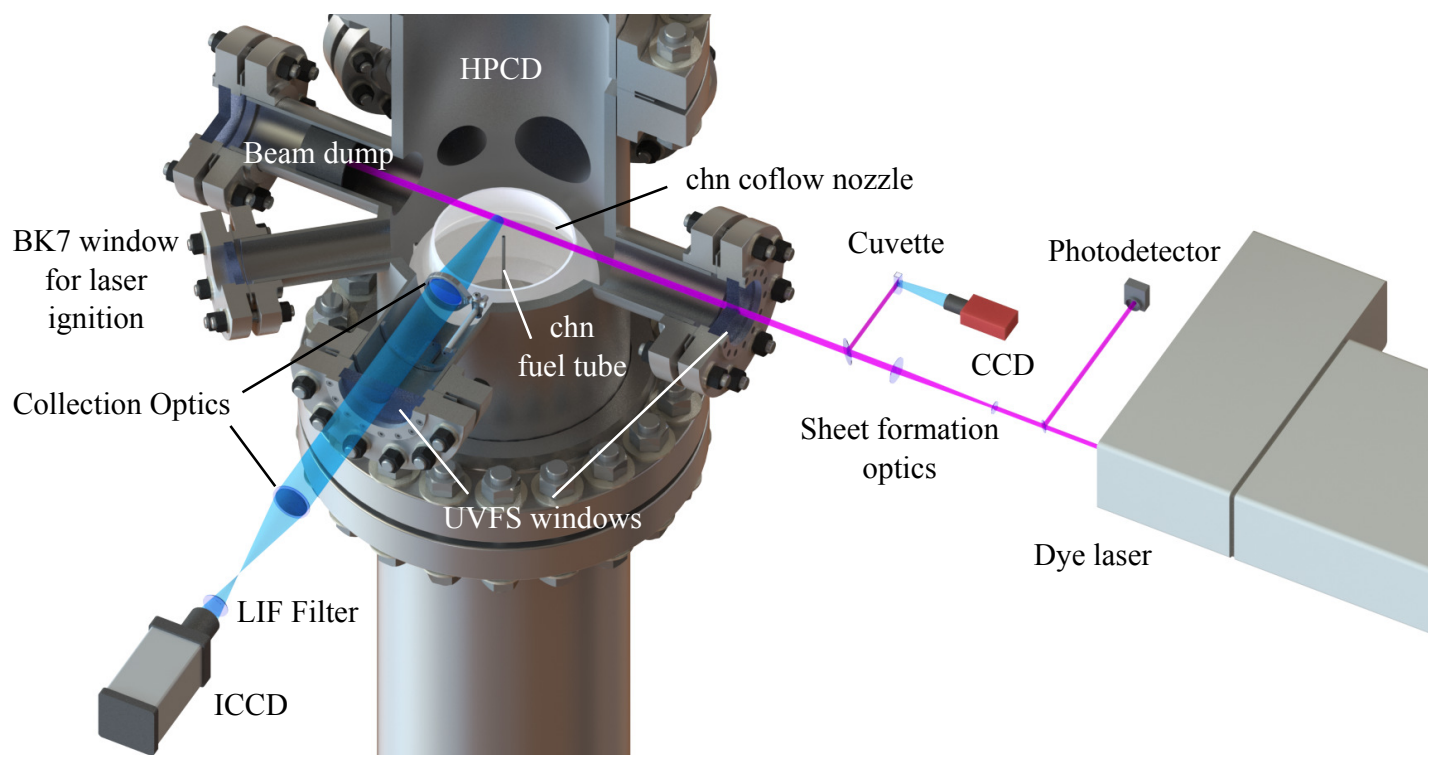

Figure 1: HPCD optical section with chn burner inside and low-speed OH-PLIF optical setup.

\subsection{Flame Conditions}

The flames investigated in this study extend the Sandia/ETH-Zurich "chnA" jet flame series to higher Reynolds numbers and pressures than what is currently available in the Turbulent Nonpremixed Flames (TNF) Workshop database [7]. The burner nozzle consists of a 570-mm long, 6.35-mm (OD) tube with squared off ends and an inner diameter of $D=4.6 \mathrm{~mm}$. A 3Dprinted axisymmetric circular coflow nozzle with an exit diameter of $250 \mathrm{~mm}$ provides air. Four sections of wire mesh and a honeycomb section ensure that the velocity profile of the coflow air is flat both radially and azimuthally. The flow rate of air entering the coflow is monitored by a thermal mass flow meter (FCI STP100). Additional air is provided to the annular region between the coflow and the interior surface of the HPCD to cool the combustion products before reaching the back pressure regulator and to prevent products (especially $\mathrm{H}_{2} \mathrm{O}$ ) from reaching the windows of the optical section.

The composition of the reactants of each flame is fixed: $40 \% \mathrm{CO}, 30 \% \mathrm{H}_{2}, 30 \% \mathrm{~N}_{2}$ by volume. All mass flow meters are calibrated with a gas flow calibrator (MesaLabs ML-1020) prior to the experiment to maintain an accuracy of $1 \%$ for all conditions. A Nd:YAG laser (Continuum Surelite III, $10 \mathrm{~Hz}, 850 \mathrm{~mJ} /$ pulse) is focused on the nonreacting flow through one of the 100mm BK7 windows of the HPCD for ignition.

A total of twelve syngas flames are investigated in this study. Operating conditions for all cases are listed in Table 1. Conditions are chosen to allow for compar- isons between flames with equal Reynolds numbers but different pressures, as well as flames with equal pressures but different Reynolds numbers. The baseline condition is identical to the atmospheric Sandia/ETHZurich "chnA" flame: it has a Reynolds number of 16,700 , a bulk jet velocity of $U_{j}=77.3 \mathrm{~m} / \mathrm{s}$, and a bulk coflow velocity of $U_{c f}=0.70 \mathrm{~m} / \mathrm{s}$. In the current study, this flame is given the designation chnA/01-01. For all other conditions, the first number in its designation is the pressure (bar), and the second number is the ratio of the flame's Reynolds number to the baseline Reynolds number. Pressures range from 1 bar to 12 bar and the Reynolds numbers range from 16,700 to 66,800 . The coflow velocity is fixed at roughly $1 / 110$ the bulk jet velocity for all flames. For comparisons purposes, laminar flames with $\mathrm{Re}=2,160$ are also examined at each pressure condition.

\section{2. $O H-P L I F$}

The optical setup for OH-PLIF is shown in Fig. 1. A tunable dye laser (Continuum ND6000+UVT) is pumped by a Nd:YAG (Continuum Powerlite DLS 9010) operating at $10 \mathrm{~Hz}$. The laser is tuned to the $Q_{1}(6)$ transition of the $\mathrm{OH}$ molecule near $\lambda=282.930 \mathrm{~nm}$ and the maximum available energy is $18-20 \mathrm{~mJ} /$ pulse. The beam is expanded to a sheet of $18 \mathrm{~mm}$ height and 200 $\mu \mathrm{m}$ thickness that crosses the burner centerline.

Prior to entering the sheet formation optics, a small fraction of the beam is directed into a biased Si photodetector (Thorlabs DET10A) to correct for shot-to- 
Table 1: Operating conditions; $p$ is the operating pressure, Re is the Reynolds number based on the jet diameter $(D=4.6 \mathrm{~mm}), U_{j}$ is the bulk jet velocity, and $U_{c f}$ is the bulk coflow velocity.

\begin{tabular}{|ccccc|}
\hline $\begin{array}{c}\text { chn } \\
\text { Flame }\end{array}$ & $\begin{array}{c}p \\
(\text { bar })\end{array}$ & $\operatorname{Re}$ & $\begin{array}{c}U_{j} \\
(\mathrm{~m} / \mathrm{s})\end{array}$ & $\begin{array}{c}U_{c f} \\
(\mathrm{~m} / \mathrm{s})\end{array}$ \\
\hline $\mathrm{A} / 01-01$ & 1 & 16,700 & 77.3 & 0.70 \\
$02-01$ & 2 & 16,700 & 38.7 & 0.35 \\
$02-02$ & 2 & 33,400 & 77.3 & 0.70 \\
$04-01$ & 4 & 16,700 & 19.3 & 0.18 \\
$04-02$ & 4 & 33,400 & 38.7 & 0.35 \\
$04-04$ & 4 & 66,800 & 77.3 & 0.70 \\
$08-01$ & 8 & 16,700 & 9.7 & 0.09 \\
$08-02$ & 8 & 33,400 & 19.3 & 0.18 \\
$08-04$ & 8 & 66,800 & 38.7 & 0.35 \\
$12-01$ & 12 & 16,700 & 6.4 & 0.06 \\
$12-02$ & 12 & 33,400 & 12.9 & 0.12 \\
$12-04$ & 12 & 66,800 & 25.8 & 0.23 \\
\hline
\end{tabular}

shot energy fluctuations. Before passing into the HPCD, a fraction of the laser sheet is directed in a UV cuvette filled with coumarin 120 dye in ethanol solution. The fluorescence signal of the dye is recorded with a CCD (AVT Prosilica GX) to correct for shot-to-shot beam profile fluctuations. Experiments are performed in the linear regime of fluorescence, implying that the laser pulse energy is adjusted for each pressure condition.

A $1024 \times 1024$ ICCD camera (Princton Instruments PI-MAX4) with UV lens (Coastal Optics, $105 \mathrm{~mm}, \mathrm{f} / 4$ ) is used to collect the $\mathrm{OH}$ fluorescence signal at $90^{\circ}$ relative to the laser sheet through a UV fused silica (UVFS) window mounted in a flange. Incoming photons are filtered using a high-transmission band-pass interference filter centered at $310 \mathrm{~nm}$ (LaVision 1108760). A 75 mm UVFS spherical lens ( $f=200 \mathrm{~mm}$ ) mounted inside the HPCD collection arm and an identical lens mounted outside the HPCD are used to increase the solid angle of collection on the ICCD, thereby increasing the spatial resolution and signal intensity. The resulting field-of-view is $25 \mathrm{~mm} \times 25 \mathrm{~mm}$, and is centered at $x / D \approx 7, r / D \approx 1$. An image of flame 04-04 with the $\mathrm{OH}-\mathrm{PLIF}$ interrogation box highlighted is presented in Fig. 2. The use of spherical singlets for the collection optics adds some distortion to the corners of the images but the distorted regions are cropped out of the analyzed region. A printed pattern of bars with increasingly fine separation is used to determine that features as small as $150 \mu \mathrm{m}$ can be distinguished with this optical arrangement, which is smaller than the width of the laser sheet. Following the arguments presented in [7], it is estimated that the smallest scalar length scale, the Batchelor scale, in the baseline condition is $\lambda_{B} \approx 510 \mu \mathrm{m}$, and in the most extreme condition, $\lambda_{B} \approx 180 \mu \mathrm{m}$. For each turbulent flame, two sets of 700 images are recorded.

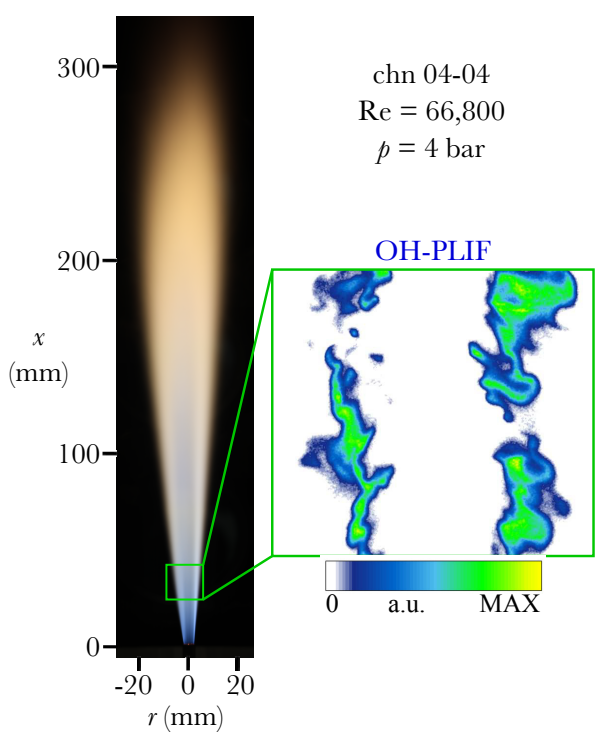

Figure 2: chn 04-04 flame with OH-PLIF region-of-interest highlighted and example of instantaneous OH-PLIF image. Flame image is a compilation of multiple DSLR images taken at three different axial locations.

\subsection{OH-PLIF Data Processing}

Images of OH-PLIF are post-processed as follows. Raw images are corrected for background noise and spatial and temporal fluctuations of laser energy density. Images are smoothed and cropped to include only one side of the flame, with the left side of the resulting image representing the fuel side and the right side representing the air side. Examples of instantaneous OH-PLIF intensity images from the three extreme flame conditions considered in this study are shown in the left column of Fig. 3. The top row image is from the low pressure, low $\mathrm{Re}$ condition (01-01). The middle row image is from the high pressure, low Re condition (12-01). And the bottom row image is from the high pressure, high $\mathrm{Re}$ condition (12-04).

Images are further post-processed to extract regions filled with $\mathrm{OH}$ and the flame front location. Edges in the images are detected with a gradient based method using the Canny algorithm $[27,28]$. The median value of the edge points returned by this algorithm are used as the binarization threshold. Images in the center column of Fig. 3 show the binarized regions, where green represents the $\mathrm{OH}$ layer for the corresponding images in the left column. While increasing pressure tends to decrease the OH-PLIF signal, for all conditions the measured signal-to-noise ratio is above 500 and this edge 


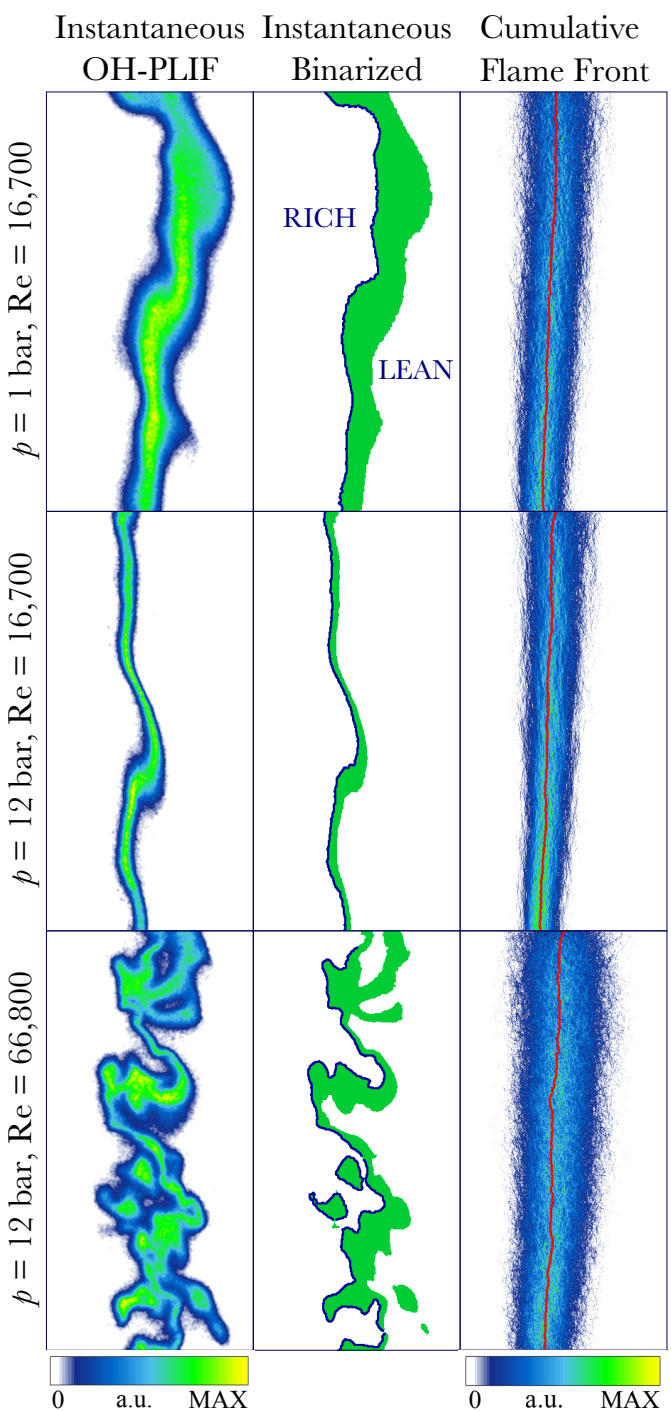

Figure 3: Instantaneous OH-PLIF images (left), corresponding binarized images (center), and cumulative flame front images for three flame conditions. Red line in cumulative flame front images represents flame front of mean $\mathrm{OH}$ intensity. Note: For all images, region corresponds to $5 \leq x / D \leq 8.2,0.2 \leq r / D \leq 1.6$.

detection method works well. More details about the image processing procedure are provided in the supplementary materials.

The flame front is the border of the $\mathrm{OH}$ layer on the fuel side, which may also be called the "rich" side [29]. The flame front for each image is then created by considering edges detected by the Canny algorithm that are on the rich side of the $\mathrm{OH}$ bodies. Flame fronts in the binarized images in the center column of Fig. 3 are represented by blue lines. The location of the flame front in the low-Re cases is relatively straightforward. It is the border of the $\mathrm{OH}$ region on the left-hand side of the image, i.e. the fuel/rich side. In the top-center image of Fig. 3, the rich and lean sides of the flame are identified. The location of the flame front in the high-Re case is more complicated due to higher corrugation of the flame front and the existence of $\mathrm{OH}$ "islands". Both of these phenomena are illustrated in the bottom-center image of Fig. 3.

\section{4. $P I V$}

PIV of non-reacting jets is used to evaluate the effects of pressure on the local Reynolds number and turbulent length scales. A Litron Nano PIV laser generates a beam $(\lambda=532 \mathrm{~nm})$ at a frequency of $5 \mathrm{~Hz}$ and with a pulse energy of $190 \mathrm{~mJ}$. A surrogate jet composition $\left(67.5 \% \mathrm{~N}_{2}, 32.5 \%\right.$ He by volume) is used. It matches the chn density and bulk jet velocity, but has a $7 \%$ greater viscosity. The jet is seeded with silicone oil. Due to pressure limitations of the seeder, only six conditions (1 to 4 bar) are investigated. Images are captured with a $1376 \times 1024$ CCD camera (LaVision Imager Intense). The resulting images are then processed using a $32 \times 32$ pixel interrogation window with $50 \%$ overlap.

The processed PIV results can be used to estimate some turbulent flow characteristics. Using data from round jet experiments in Hussein et al. (1994), the axial integral length scale, $L_{11}$, is proportional to the full width at half-maximum of the mean axial velocity profile, $r_{1 / 2}: L_{11}=0.41 r_{1 / 2}$ on the centerline [30]. An estimate of the Taylor microscale is given by $\lambda_{T}=u^{\prime}(15 v / \varepsilon)^{1 / 2}$, where $u^{\prime}$ is the RMS of velocity fluctuations. The turbulent kinetic energy dissipation rate is found by using the empirical correlation $\varepsilon=0.33\left(u^{\prime}\right)^{3} / L_{11}$ [25]. The Reynolds number based on the Taylor microscale is $\operatorname{Re}_{\lambda}=u^{\prime} \lambda_{T} / v$. Lastly, the Kolmogorov scale is given by $\eta=\left(v^{3} / \varepsilon\right)^{1 / 4}$.

Reynolds numbers and turbulence length scales are summarized in Table 2. The data in this table reveal that the pressure has only a small effect on the turbulence characteristics of the jet in comparison to differences in bulk flow Reynolds number. In the cases represented here, the Taylor microscale is resolved in the OH-PLIF measurements, and judging by the trends in this length scale with pressure, it is expected to remain resolved by this technique at the most extreme condition (12-04). Some caution should be exercised in applying these results to the reacting chn jet flames due to the fact that the $\mathrm{N}_{2} / \mathrm{He}$ jets are non-reacting, the viscosity is not exactly matched, and the region of interest $(x / D=7)$ is closer to the nozzle exit than what is generally considered to be the self-similar region of high-Reynolds number turbulent jets. 
Table 2: Turbulent flow characteristics as estimated from PIV data using a velocity/density-matched $\mathrm{N}_{2} / \mathrm{He}$ jet.

\begin{tabular}{|cccccc|}
\hline $\begin{array}{c}p \\
(\mathrm{bar})\end{array}$ & $\begin{array}{c}U_{j} \\
(\mathrm{~m} / \mathrm{s})\end{array}$ & $\begin{array}{c}L_{11} \\
(\mathrm{~mm})\end{array}$ & $\begin{array}{c}\lambda_{T} \\
(\mu \mathrm{m})\end{array}$ & $\mathrm{Re}_{\lambda}$ & $\begin{array}{c}\eta \\
(\mu \mathrm{m})\end{array}$ \\
\hline 1 & 77.3 & 2.0 & 570 & 160 & 23 \\
2 & 38.7 & 2.1 & 500 & 190 & 19 \\
2 & 77.3 & 2.0 & 340 & 270 & 11 \\
4 & 19.3 & 2.1 & 490 & 190 & 18 \\
4 & 38.7 & 2.0 & 340 & 270 & 10 \\
4 & 77.3 & 2.1 & 240 & 400 & 6 \\
\hline
\end{tabular}

\section{Results}

In the following discussion, the area of the $\mathrm{OH}$ layer is the area of the green region, and the length of the flame front is the length of the blue line, shown in the center column of Fig. 3. The blue line in each image has been widened for clarity, but for processing purposes, the thickness of the flame front is 1 pixel. Images in the right column of Fig. 3 show the accumulation of flame fronts over the entire series of images for each of the three conditions. It represents the probability of finding a flame front at a given position. The distribution of flame fronts is similar for the low-Re cases, but slightly narrower and more concentrated in the 12 bar case, and is somewhat wider for the high-Re case. In each image, a red line is drawn which represents the "flame front" of the mean of the respective $\mathrm{OH}$ intensity images. In all cases, it is a nearly straight line, and it serves as the reference flame front for each condition.

In comparing the three images in the left column, two features are immediately apparent. First, the $\mathrm{OH}$ layer is much thicker in the low-pressure image than the highpressure images. Second, the $\mathrm{OH}$ layer is much more corrugated in the high-Re image than the low-Re images. Both of these effects have been quantified.

\subsection{OH Layer Thickness}

For the low-Re flame conditions which show little corrugation of the flame front, the $\mathrm{OH}$ layer thickness can be approximated by dividing the area of the $\mathrm{OH}$ layer by the length of the flame front. To understand the effect of pressure on the $\mathrm{OH}$ layer thickness, the mean of $\sim 1400 \mathrm{OH}$ layer thickness values for each of the five low-Re conditions is plotted as a function of pressure in Fig. 4. Values measured with the laminar diffusion flames are also plotted for comparison. The trend of decreasing $\mathrm{OH}$ layer thickness with pressure is present for both laminar and turbulent flames. Relative to the laminar flames, the turbulent flames are characterized by a thinner $\mathrm{OH}$ layer and the rate of thinning as a function

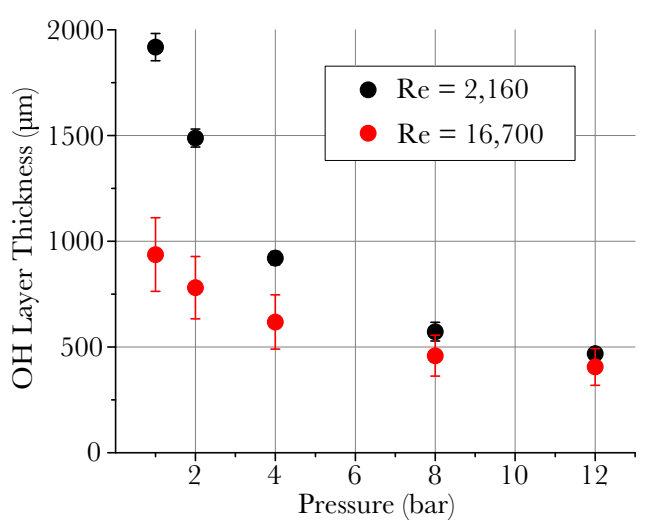

Figure 4: Mean $\mathrm{OH}$ layer thickness as a function of pressure for laminar and turbulent nonpremixed flames. Error bars represent standard deviations.

of pressure is less. The turbulent $\mathrm{OH}$ layers at $p=12$ bar are less than half as thick as in the $p=1$ bar turbulent flames. As pressure is known to increase 3-body recombination rates, thereby thinning the $\mathrm{OH}$ layer, these results are expected. The fact that laminar flames have thicker layers than turbulent flames is likely due to the lower strain rate experienced by laminar flames [31].

\subsection{Flame Front Corrugation}

A corrugation factor is used to quantify the effect of pressure and $\mathrm{Re}$ on the wrinkling of the flame front. This factor is defined in any given OH-PLIF image as the length of the flame front divided by the length of the mean flame front based on time-averaged OH-PLIF images. Examples of this mean flame front are shown as a red line in the right column of Fig. 3. The corrugation factor, defined in this way, gives an intuitive measure of how "straight" or how "wrinkled" the flame front is.

In Fig. 5a, the distribution of the corrugation factor is displayed for different pressures, grouped by Re. For the lowest Re cases, the distributions are sharp, with a peak value near 1 , meaning very little wrinkling of the flame front. The distributions are quite similar but show a clear progression from narrow to wider as the pressure decreases and this is attributed to the decrease of the $\mathrm{OH}$ layer thickness. Wider $\mathrm{OH}$ layers can support larger features (for instance, compare the top two cases in Fig. 3), resulting in longer flame fronts at low pressure. For the two high Re groups, this trend disappears and the distributions are practically overlapping, indicating no discernible impact of pressure on the wrinkling of the flame front.

Moving left-to-right across Fig. 5a, it is clear that changes in $\mathrm{Re}$, as opposed to $p$, have an effect on the wrinkling of the flame front. This is in agreement with 
the results of the PIV measurements, which show that increasing the jet Reynolds number has a far greater impact on $\lambda_{T}$ and $\operatorname{Re}_{\lambda}$ than increasing the pressure. Having resolved the Batchelor scale in all cases, the results of Fig. 5a should not be affected by the resolution of the technique.

\subsection{Flame Front Location}

In the right column of Fig. 3, the flame brush yielded by accumulating 1400 instantaneous flame fronts in the high-Re case appears to be much wider than in the lowRe cases. This could be a result of increased corrugation, increased radial movement of the flame front, or both. To distinguish these two possibilities, the centroid of the flame front in the region $6.4 \leq x / D \leq 6.8$ is calculated for each image and the distribution of its radial location is shown in Fig. 5b. As with the corrugation factor, there is no discernible effect of pressure on the distribution of the flame front radial position. By comparing the distributions for the same pressure but different $\mathrm{Re}$, it may be seen that increases in $\mathrm{Re}$ tend to slightly widen the distribution of flame front location. This effect, however, is small in comparison to the effect of Re on corrugation. Therefore, the increase of flame brush width as $\mathrm{Re}$ is increased is attributed to the increase of corrugation.

\subsection{Local Extinction}

As part of the flame-front-detection process, $\mathrm{OH}$ "islands" are identified and classified as belonging to the fuel side of the image, the air side of the image, or the center. From the number of islands at the center of each image, the number of holes in the $\mathrm{OH}$ layer, a measure of the degree of local extinction, is easily determined. This procedure follows closely the work of [29]. The resulting PDFs of holes per image are displayed in Fig. 5c. A consistent trend of decreasing numbers of holes per image with increasing pressure is seen for all Reynolds numbers. At $\operatorname{Re}=16,700$, the chance of finding any local extinction is very close to zero except for the $p=1$ bar condition. At $\operatorname{Re}=33,400$, the $p=2$ bar condition experiences the most local extinction, followed by the $p$ $=4$ bar condition, and the $p=8$ and 12 bar cases experience the least local extinction. For the $\mathrm{Re}=66,800, p$ $=4$ bar case (see Fig. 2), the probability of finding one hole in an image is actually greater than the probability of finding an unbroken $\mathrm{OH}$ layer. For constant Re conditions, the bulk jet velocity decreases as the pressure increases (see Table 1), so these trends may be understood as the result of decreasing exit strain rates.

\section{Conclusions}

A high-pressure rig and high-quality OH-PLIF images have been used to examine the structure of canonical, axisymmetric turbulent nonpremixed syngas flames under a novel set of conditions. This marks the first time a TNF canonical jet flame has been operated at elevated pressures. For each condition, measurements were taken in a small region of the flame near the nozzle exit. For these turbulent nonpremixed syngas flames, it is possible to increase the Reynolds number to a very large value of $\mathrm{Re}=66,800$ via the pressure, while keeping the flame stable.

The $\mathrm{OH}$ layer thickness of turbulent nonpremixed syngas flames decreases with increasing pressure, much as the $\mathrm{OH}$ layer thickness of laminar flames does, but at a slower rate. Corrugation of the flame front always increases with Reynolds number. Pressure has a minor effect on corrugation at low Reynolds number but no effect at high Reynolds numbers. The mean radial flame front location is relatively insensitive to both Reynolds number and pressure. Increasing the Reynolds number widens the flame brush through enhanced corrugation. As the bulk jet velocity and exit strain rate decrease with increasing pressure, for fixed Reynolds number, the probability of local extinction decreases.

Pressure is a powerful parameter that allows examining flame/turbulence interactions for Reynolds numbers characteristic of practical devices $(\operatorname{Re}>100,000)$, that are very hard to achieve under atmospheric conditions. Future studies will investigate if the findings hold for other fuels, and other TNF canonical jet flames.

\section{Acknowledgments}

The research reported in this publication was supported by funding from King Abdullah University of Science and Technology (KAUST).

\section{References}

[1] A. R. Masri, R. W. Dibble, R. S. Barlow, Prog. Energy Combust. Sci. 22 (1996) 307-362.

[2] R. S. Barlow, Proc. Combust. Inst. 31 (2007) 49-75.

[3] R. S. Barlow, S. Meares, G. Magnotti, H. Cutcher, A. R. Masri, Combust. Flame 162 (2015) 3516-3540.

[4] T. Stahler, D. Geyer, G. Magnotti, P. Trunk, M. J. Dunn, R. S. Barlow, A. Dreizler, Proc. Combust. Inst. 36 (2017) 1947-1955.

[5] M. S. Sweeney, S. Hochgreb, M. J. Dunn, R. S. Barlow, Combust. Flame 159 (2012) 2912-2929.

[6] F. Fuest, G. Magnotti, R. S. Barlow, J. A. Sutton, Proc. Combust. Inst. 35 (2015) 1235-1242.

[7] R. S. Barlow, G. J. Fiechtner, C. D. Carter, J.-Y. Chen, Combust. Flame 120 (2000) 549-569. 

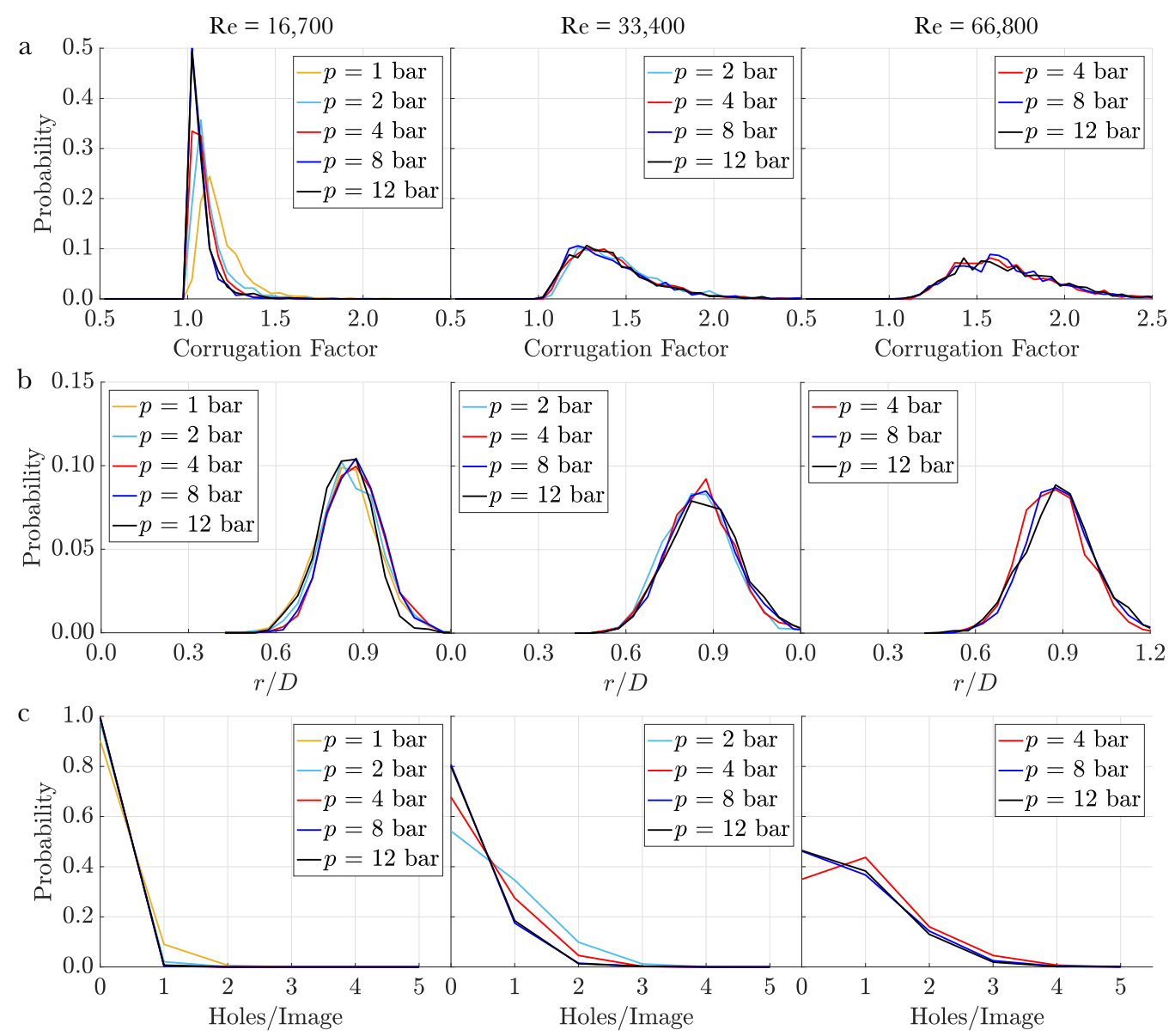

Figure 5: Probabilities of (a) corrugation factor, (b) radial flame front position, and (c) holes per image for multiple pressures, grouped by Reynolds number: $\operatorname{Re}=16,700$ (left), $\operatorname{Re}=33,400$ (center), $\operatorname{Re}=66,800$ (right).

[8] J. H. Frank, R. S. Barlow, C. Lundquist, Proc. Combust. Inst. 28 (2000) 447-454.

[9] A. R. Masri, R. W. Dibble, Symp. (Int.) Combust. 22 (1988) 607-618.

[10] Y. Ichikawa, Y. Otawara, H. Kobayashi, Y. Ogami, T. Kudo, M. Okuyama, S. Kadowaki, Proc. Combust. Inst. 33 (2011) 1543-1550.

[11] J. Wang, M. Zhang, Z. Huang, T. Kudo, H. Kobayashi, Combust. Flame 160 (2013) 2434-2441

[12] P. Venkateswaran, A. D. Marshall, J. M. Seitzman, T. C. Lieuwen, J. Eng. Gas Turbines Power 136 (2014) 011504.

[13] R. Sadanandan, P. Kutne, A. Steinberg, W. Meier, Flow, Turbul. Combust. 89 (2012) 275-294.

[14] R. W. Bilger, Symp. (Int.) Combust. 22 (1988) 475-488.

[15] R. S. Barlow, J. H. Frank, Symp. (Int.) Combust. 27 (1998) 1087-1095.

[16] J. A. Sutton, J. F. Driscoll, Combust. Flame 160 (2013) 17671778.

[17] C. K. Law, Combustion Physics, Cambridge University Press, 1 st edition, 2006.

[18] F. N. Egolfopoulos, C. K. Law, Combust. Flame 80 (1990) 7-16.

[19] F. Halter, C. Chauveau, N. Djebaili-Chaumeix, I. Gökalp, Proc. Combust. Inst. 30 (2005) 201-208.

[20] T. C. Lieuwen, V. Yang, R. Yetter (Eds.), Synthesis Gas Com- bustion: Fundamentals and Applications, CRC Press, 2010.

[21] H. Kobayashi, Exp. Therm. Fluid Sci. 26 (2002) 375-387.

[22] T. F. Guiberti, M. Juddoo, D. A. Lacoste, M. J. Dunn, W. L. Roberts, A. R. Masri, Proc. Combust. Inst. 36 (2017) 17771784.

[23] B. Coriton, M. Zendehdel, S. Ukai, A. Kronenburg, O. T. Stein, S. K. Im, M. Gamba, J. H. Frank, Proc. Combust. Inst. 35 (2015) 1251-1258.

[24] M. Kim, Y. Yoon, Proc. Combust. Inst. 31 (2007) 1609-1616.

[25] P. S. Kothnur, M. S. Tsurikov, N. T. Clemens, J. M. Donbar, C. D. Carter, Proc. Combust. Inst. 29 (2002) 1921-1927.

[26] C. Chi, G. Janiga, A. Abdelsamie, K. Zähringer, T. Turányi, D. Thévenin, Flow, Turbul. Combust. 98 (2017) 1117-1132.

[27] J. Canny, IEEE Trans. Pattern Anal. Mach. Intell. 8 (1986) 679698.

[28] A. E. Bayley, Y. Hardalupas, A. M. Taylor, Exp. Fluids 52 (2012) 963-983

[29] S. A. Kaiser, J. H. Frank, Proc. Combust. Inst. 32 (2009) 16391646.

[30] H. J. Hussein, S. P. Capp, W. K. George, J. Fluid Mech. 258 (1994) 31-75.

[31] C. J. Sung, J. B. Liu, C. K. Law, Combust. Flame 102 (1995) 481-492. 